\title{
The origin of Guideline Daily Amounts and the Food Standards Agency's guidance on what counts as 'a lot' and 'a little'
}

\author{
Mike Rayner ${ }^{1, *}$, Peter Scarborough ${ }^{1}$ and Carol Williams ${ }^{2}$ \\ 'British Heart Foundation Health Promotion Research Group, Department of Public Health, University of Oxford, \\ Oxford OXI 7LF, UK: ${ }^{2}$ Centre for International Child Health, Institute of Child Health, 30 Guilford Street, \\ London WCIN 1EH, UK
}

Submitted 7 August 2003: Accepted 10 0ctober 2003

\begin{abstract}
Objective: This paper provides the rationale for the Guideline Daily Amounts (GDAs) for fat, saturated fat and other nutrients that appear on food labels in the UK. These GDAs are provided voluntarily by manufacturers and retailers and were developed to help people make better use of nutrition labelling - the format of which is prescribed by the European Union's nutrition labelling directive. The paper also describes the basis to some Rules of Thumb for what counts as 'a lot' or 'a little' of fat, saturated fat and other nutrients, in an individual food.

Design: The paper gives the background to, and purpose of, the GDAs and Rules of Thumb and explains how they were calculated. It briefly describes their subsequent usage by food producers and others.

Results: Both GDAs and the Rules of Thumb first appeared in a leaflet developed by the authors and published in 1996 by the Ministry of Agriculture, Fisheries and Food. GDAs for fat, saturated fat and energy were adopted subsequently by the Institute of Grocery Distribution and then by many retailers and some manufacturers. The Rules of Thumb for fat, saturated fat, sugar and sodium have recently been republished in some leaflets published by the Food Standards Agency in the UK.

Conclusions: GDAs and Rules of Thumb may provide useful ways of helping consumers make sense of nutrition labelling. The current GDAs and the Rules of Thumb could usefully be updated in the light of recent developments.
\end{abstract}

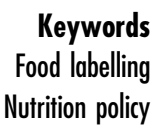

In late 1994, we (M.R. and C.W.) approached the Ministry of Agriculture, Fisheries and Food (MAFF) in the UK with a proposal to develop a leaflet that aimed to help consumers make better use of nutrition labelling. The leaflet was published by MAFF in 1996 as one of their Food Sense series with the title Use your Label: Making Sense of Nutrition Information ${ }^{1}$.

The format for nutrition labelling of foods in the UK is governed by the European Union's (EU) nutrition labelling directive $^{2}$. The directive prescribes two basic formats: a minimum list of the energy, protein, carbohydrate and fat contents or a longer list of the energy, protein, carbohydrate, sugar, fat, saturated fat, fibre and sodium contents. Nutrient content information must be given on a per $100 \mathrm{~g}$ basis and may, in addition, be given per serving.

There is considerable evidence that consumers find nutrition labelling in the EU-prescribed formats difficult to interpret and $\mathrm{use}^{3}$. In developing Use your Label we decided to test two methods of helping consumers interpret nutrition labelling: Guideline Daily Amounts
(GDAs) and some Rules of Thumb for what counts as 'a lot' or 'a little' of fat, saturated fat and other nutrients, in an individual food.

The aim of providing GDAs was to give consumers 'benchmarks' against which they could judge - from the nutrition labelling - the amount of a nutrient a food would provide relative to a recommended amount. We also thought that consumers might theoretically be able to use GDAs as 'target' figures - in the same way as some weightloss programmes set participants target limits for the number of calories they should eat in a day.

GDAs are therefore nutrient intake levels that individuals should use as a target if the population is to achieve agreed nutrient goals. When Use your Label was published, the UK Government's Committee on Medical Aspects of Food and Nutrition Policy (COMA) had responsibility for developing nutrient goals for the UK population and these were published in its reports in particular its 1991 report on Dietary Reference Values for Food Energy and Nutrients for the 
United Kingdom ${ }^{4}$. This responsibility now lies with the Scientific Advisory Committee on Nutrition, which reports to the Food Standards Agency (FSA) and the Department of Health.

Consumers often develop 'rules of thumb' or 'cognitive heuristics' when purchasing foods on health grounds'. Research into consumer use of food labelling using protocol analysis ${ }^{6}$ has uncovered numerous examples of cognitive heuristics, mostly related to preconceptions about nutrition such as 'I think vegetable fat is better for you than animal fat', but some related to the use of nutrition labelling for judging nutrient content levels in foods such as 'I thought the numbers looked quite low'. The advice about what counts as a lot or a little in Use your Label was primarily designed to provide consumers with more evidence-based Rules of Thumb to use when using nutrition labelling.

Testing the two approaches involved asking lowincome consumers to undertake tasks involving nutrition labelling after they had been exposed to GDAs or Rules of Thumb in draft camera-ready leaflets. Both types of information improved respondents' performance in the tasks compared with a control, but no one method was more effective than the other and both the GDAs and the Rules of Thumb were included in Use your Label when it was finally published in $1996^{7}$.

Use your Label was the first official publication in the UK to provide GDAs. It gave GDAs for five key nutrients: fat, saturated fat, sodium, sugar and fibre. It also gave Rules of Thumb for what counts as a lot and a little of these nutrients in a food. This paper gives the rationale for the GDAs and the Rules of Thumb in Use your Label, and explains how they were calculated. GDAs for energy, fat and saturated fat are now commonly found on food labels in the UK. The Rules of Thumb have been used less widely than the GDAs but have recently been republished by the FSA in a series of leaflets ${ }^{8}$.

The Rules of Thumb are similar to the compositional criteria for nutrition claims such as 'low fat', 'high fibre', etc. The European Commission has recently published a proposal for a regulation including legally enforceable compositional criteria for nutrition claims ${ }^{9}$ derived from the Codex Alimentarius Commission's guidelines for nutrition claims ${ }^{10}$. However, the Codex criteria for nutrition claims have no transparent or rational basis. The way the Rules of Thumb were developed could provide a more transparent and rational method for developing criteria for nutrition claims.

Use your Label is now out of print, but the GDAs and the Rules of Thumb are still being used in a variety of ways. We recommend that the FSA republish the GDAs and update the Rules of Thumb. In this paper we suggest ways in which the GDAs and the Rules of Thumb might be updated in the light of developments since Use your Label was published.

\section{The basis to the Guideline Daily Amounts}

Use your Label gave the following table of 'Daily Guideline Intakes'. In this paper these will subsequently be called Guideline Daily Amounts (GDAs) in line with current usage.

$\begin{array}{lrr} & \text { MEN } & \text { WOMEN } \\ \text { Fat } & 95 \mathrm{~g} & 70 \mathrm{~g} \\ \text { Saturates } & 30 \mathrm{~g} & 20 \mathrm{~g} \\ \text { Sodium } & 2.5 \mathrm{~g} & 2 \mathrm{~g} \\ \text { Fibre } & 20 \mathrm{~g} & 16 \mathrm{~g}\end{array}$

The text of the leaflet also stated that these GDAs 'are based on an average-sized man and woman, with an average level of physical activity. An average man needs about $2500 \mathrm{kcal}$ a day and an average woman needs about 2000 kcal.'

In developing the table of GDAs we first had to decide the units in which they needed to be given. Since Use your Label was designed to interpret nutrition labelling as prescribed by the EU's nutrition labelling directive, we decided we needed to use the same units (grams) for GDAs as prescribed for nutrient levels.

Second, we had to decide whether to give different figures for men and women or just one (sexes-combined) figure. There were two reasons for giving a single figure: (1) a single set of numbers might be easier to remember and (2) a double set of figures might imply spurious accuracy - body size and activity pattern being as important determinants of requirements (actual or recommended) as gender. On the other hand, we thought consumers would expect different targets for men and women and a sexes-combined figure would generally overestimate desirable intakes for women. Alcohol targets have been set differently for men and women ${ }^{11}$. So we decided that we would give two figures.

Third, we had to decide which nutrients required GDAs. The longer format for nutrition labelling prescribed by the EU directive requires labelling of energy, protein, carbohydrate, sugar, fat, saturated fat, fibre and sodium. Of these we chose fat, saturated fat, sodium, fibre and sugar because we thought these were the main nutrients that consumers should focus on when looking at the nutrition label.

Fat and saturated fat were, in 1996, the focus of government policy on diet and nutrition. The UK Government's 'Health of the Nation' strategy - published in 1992 - had set targets for fat and saturated fat intake ${ }^{12}$. Sodium consumption was of less concern but COMA's 1994 report on Nutritional Aspects of Cardiovascular Disease had set a population dietary goal ${ }^{13}$.

COMA had indicated that people should be more concerned about their non-milk extrinsic sugar intake than their total sugar intake $e^{4,14}$. However, nutrition labelling only gives information about the total amount of sugar in 
products, so we provided GDAs for total sugar rather than non-milk extrinsic sugar.

When Use your Label was being written, food manufacturers were using various methods for calculating the fibre content of foods and there was (and still is) no legal definition of fibre for nutrition labelling. Since COMA had recommended the Englyst method for measuring fibre (or non-starch polysaccharide) ${ }^{4}$, we thought it would be most useful to give GDAs for fibre as measured using this method.

In Use your Label we did not give GDAs for energy but stated in the accompanying text that 'an average man needs about $2500 \mathrm{kcal}$ a day and an average women needs about $2000 \mathrm{kcal}$ '. At the time, the principal argument for giving GDAs for energy was that consumer research had suggested that consumers, when reading food labels, commonly looked for the amount of calories on food packets and expressed a need for a benchmark or target to relate this information to ${ }^{15}$. The principal argument against was that COMA had recommended that on average people in the UK do not need to consume more or less energy ${ }^{4}$, and we thought that giving people an energy target might encourage some people to eat unnecessarily more energy and some people to eat unnecessarily less. In particular, we thought that giving GDAs for energy might encourage people who have an energy need that is less than the guideline amount to eat up to that amount, so putting on weight.

There did not appear to be any necessity to provide GDAs for protein as COMA had concluded that protein intakes in the UK are above the recommended requirement ${ }^{4}$, and we decided not to give GDAs for total carbohydrate because of consumer confusion about the role of carbohydrates in the diet ${ }^{15}$.

Fourth, we needed to decide the precise population dietary goals and other figures from which to calculate the
GDAs. We decided that the GDAs in Use your Label should be derived from the population dietary goals in two official COMA reports: the 1991 report on Dietary Reference Values for Food Energy and Nutrients for the United Kingdom ${ }^{4}$ (COMA 1991) and the 1994 report on Nutritional Aspects of Cardiovascular Disease ${ }^{13}$ (COMA 1994). These could now be supplemented with a COMA report on Nutritional Aspects of the Development of Cancer ${ }^{16}$ and the 2003 report of the Scientific Advisory Committee on Nutrition (the successor to COMA) on Salt and Health ${ }^{17}$. However, these two more recent reports have not changed any of the relevant population dietary goals.

Table 1 gives the population goals from which the GDAs in Use your Label were derived and the GDAs to one decimal point.

\section{The basis to the Rules of Thumb}

The text of Use your Label suggests 'Try using these rules of thumb to give you an idea of how much is a lot or a little of the most important nutrients for making healthy choices', and gives the following table:

$\begin{array}{ll}\text { A LOT } & \text { A LITTLE } \\ \text { These amounts or more: } & \text { These amounts or less: } \\ 10 \mathrm{~g} \text { of sugars } & 2 \mathrm{~g} \text { of sugars } \\ 20 \mathrm{~g} \text { of fat } & 3 \mathrm{~g} \text { of fat } \\ 5 \mathrm{~g} \text { of saturates } & 1 \mathrm{~g} \text { of saturates } \\ 3 \mathrm{~g} \text { of fibre } & 0.5 \mathrm{~g} \text { of fibre } \\ 0.5 \mathrm{~g} \text { of sodium } & 0.1 \mathrm{~g} \text { of sodium }\end{array}$

The text then reads: 'For whole meals or main dishes look at the amount you get in a serving. For other foods including snack foods, ingredients in recipes and foods such as margarine which you eat in relatively small amounts, look at the amount of nutrient you get in $100 \mathrm{~g}$ '.

Table 1 Basis to, and exact figures for, the Guideline Daily Amounts (GDAs) in Use your Label

\begin{tabular}{|c|c|c|c|c|}
\hline Population dietary goal & GDA for & Men & Women & Sexes combined \\
\hline None* & [Energy] & $2550 \mathrm{kcal}$ & $1940 \mathrm{kcal}$ & $2245 \mathrm{kcal}$ \\
\hline $33 \%$ energy from fat $\dagger$ & Fat & $93.5 \mathrm{~g}$ & $71.1 \mathrm{~g}$ & $82.3 \mathrm{~g}$ \\
\hline $10 \%$ energy from saturated fat $\ddagger$ & Saturates & $28.0 \mathrm{~g}$ & $21.6 \mathrm{~g}$ & $24.8 \mathrm{~g}$ \\
\hline $2.3 \mathrm{~g}_{\text {day }}{ }^{-1}$ from sodium $\S$ & Sodium & $2.6 \mathrm{~g}$ & $2.0 \mathrm{~g}$ & $2.3 \mathrm{~g}$ \\
\hline $10 \%$ energy from non-milk extrinsic sugar & Sugar & $68.0 \mathrm{~g}$ & $51.7 \mathrm{~g}$ & $59.9 \mathrm{~g}$ \\
\hline $18 \mathrm{~g} \mathrm{day}^{-1}$ from non-starch polysaccharide\|l & Fibre & $20.4 \mathrm{~g}$ & $15.6 \mathrm{~g}$ & $18.0 \mathrm{~g}$ \\
\hline
\end{tabular}

* Use your Label' did not give GDAs for energy but did provide the energy basis for its GDAs for fat, saturated fat, etc. This was the 'Estimated Average Requirement' for energy for people aged 19-50 years from the 1991 report of the Committee on Medical Aspects of Food and Nutrition Policy (COMA) on Dietary Reference Values for Food Energy and Nutrients for the United Kingdom ${ }^{4}$ (COMA 1991). The amounts were rounded to the nearest $500 \mathrm{kcal}^{\text {. }}$

$\dagger, \ddagger$ 'Dietary Reference Values' for fat and saturated fat for adults as a percentage of daily total energy intake (population averages) from COMA 1991. (We chose this population goal for fat rather than that of COMA's 1994 report on Nutritional Aspects of Cardiovascular Disease ${ }^{13}$ (COMA 1994) (about 35\%) because it was more stringent.) We assumed that fat and saturated fat have $9 \mathrm{kcal}$ per gram ${ }^{18}$. GDAs were rounded to the nearest $5 \mathrm{~g}$.

$\S$ COMA 1994 recommends that the 'average intake' of salt should be reduced to $6 \mathrm{~g} \mathrm{day}^{-1}$; equivalent to $2.3 \mathrm{~g}$ of sodium. The recent report from the Scientific Advisory Committee on Nutrition ${ }^{17}$ endorses this population dietary goal. GDAs for men and women were made proportional to energy intake. GDAs were rounded to the nearest $0.5 \mathrm{~g}$.

I Dietary Reference Value for non-milk extrinsic sugar for adults as a percentage of daily total energy intake (population average) from COMA 1991. We assumed that sugar has $3.75 \mathrm{kcal}$ per gram ${ }^{18}$. GDAs were rounded to then nearest $5 \mathrm{~g}$. Note that the GDAs for sugar were derived from a population dietary goal for non-milk extrinsic sugar and not total sugar. We used a goal for non-milk extrinsic sugar because COMA had not published a population goal for total sugar. We could have developed our own population goal for total sugar (see Appendix) but we wanted to derive GDAs from officially agreed population goals and we also thought that most of the sugar in products that carry nutrition labelling was non-milk extrinsic sugar rather than milk sugar or intrinsic sugar.

II Dietary Reference Value for fibre (non-starch polysaccharide) from COMA 1991. GDAs for men and women were made proportional to energy intake. GDAs were rounded to the nearest gram. 
The text of Use your Label gives some explanation of why people should look at the per serving or the per $100 \mathrm{~g}$ information depending on the type of food: 'Judging whether a food is an overall healthy choice or not will depend on how you eat it as well as how much nutrient it contains. You'd expect main meals or main dishes to provide more of ALL nutrients than snacks such as biscuits and crisps, or foods like jam and margarine you eat in small quantities.'

When developing the Rules of Thumb we were, of course, conscious of previous attempts to develop criteria for judging whether a food has a lot or a little of particular nutrients. In particular we were aware that the UK Government's Food Advisory Committee (FAC) had proposed criteria for nutrition claims such as 'low fat', 'low sugar', 'high fibre', etc. ${ }^{19}$ and that the Codex Alimentarius Commission was developing similar criteria on an international basis ${ }^{10}$. We were also aware of the Coronary Prevention Group's nutrition banding scheme, which sets levels for 'high', 'medium high', 'medium low' and 'low' fat, fibre, etc. ${ }^{20,21}$. We chose the phrases 'a lot' and 'a little' for our Rules of Thumb to distinguish them from these other schemes for defining 'high', 'low', etc.

In developing the Rules of Thumb we first had to decide which nutrients we would provide rules for. We decided that we would provide Rules of Thumbs for all those nutrients for which we provided GDAs, i.e. fat, saturated fat, sodium, sugar and fibre.

Second, we had to decide whether to direct people's attention to the per $100 \mathrm{~g}$ or the per serving information on the food label. There has always been a debate about how nutrient content levels should be defined e.g. when making nutrition claims. The three main options are per $100 \mathrm{~g}$, per serving or portion and per $100 \mathrm{~kJ}$. In developing our Rules of Thumb we only had the per $100 \mathrm{~g}$ and per serving options because these are the only ways nutrient levels are displayed in nutrition labelling.

We decided that the Rules of Thumb should direct people's attention to per serving information in the case of main meals and main dishes and to per $100 \mathrm{~g}$ information for other foods. This approach was designed to take account of the different ways foods are eaten and the variable water content of foods in a similar fashion to the FAC criteria for nutrition claims. The FAC criteria for making a 'low fat' claim, for example, were that the food should have less than $5 \mathrm{~g} / 100 \mathrm{~g}$ of fat AND less than $5 \mathrm{~g} /$ serving.

Both the FAC's and our approaches aim to deal with foods which provide only a little of a nutrient on a per $100 \mathrm{~g}$ basis, but because they are eaten in servings larger than $100 \mathrm{~g}$ may contribute a large amount to the diet (e.g. sodium with soups, ready meals, etc.) and also with foods which provide only a little of a nutrient on a per serving basis, but because they are eaten frequently may also contribute a large amount of the nutrient to the diet (e.g. fat with spreads).
Finally we had to decide the numerical cut points for a lot and a little. An obvious source of figures was the criteria for nutrition claims that had been developed by the FAC or were being developed by the Codex Alimentarius Commission. However, this type of criterion would have been suitable only for some of the Rules of Thumb. Clearly they could not have been used for the criteria 'a lot of fat', 'a little fibre', etc. because food producers do not make 'high fat', 'low fibre' and other such claims. Furthermore, it was not clear that FAC or Codex criteria had been set on any consistent or rational basis.

In theory, there were various ways in which the cut-off points could have been set consistently; e.g. in relation to:

1. population dietary goals or individual dietary targets such as GDAs;

2. nutrient intakes such as mean population intakes; or

3. nutrient content levels in a defined sample of foods.

The FAC had given some reasons for their choice of levels for their criteria for nutrition claims. In the case of "high fibre" claims, they had stated that "The minimum quantities recommended to control "high fibre" (6g per $100 \mathrm{~g}$ ), "source of fibre" (3 g per $100 \mathrm{~g}$ ) claims were related to the figure of $18 \mathrm{~g}$ suggested by a number of sources as a reasonable target for fibre intake per day', i.e. a third and a sixth, respectively ${ }^{19}$.

The Coronary Prevention Group criteria had also been set in relation to population dietary goals. In their case the cut point between the 'medium low' and 'medium high' bands was the population dietary goal (e.g. for fat it was $33 \mathrm{~kJ} / 100 \mathrm{~kJ}$ ). And the cut points between 'low' and 'medium low' and between 'high' and 'medium high' were $50 \%$ above and $50 \%$ below the population dietary goal (e.g. for fat it was $16.5 \mathrm{~kJ} / 100 \mathrm{~kJ}$ and $49.5 \mathrm{~kJ} / 100 \mathrm{~kJ}$ ).

So, in developing the Rules of Thumb for Use your Label, we decided that the cut points should bear a consistent relationship to the GDAs. We decided that 'a lot' should be one-fifth of the GDA and 'a little' should be one-thirtieth. In deciding the exact proportions consideration was given to:

1. the proportions of foods which qualify as containing a lot or a little of each of the nutrients; and

2. the similarity of the Rules of Thumb to the FAC and Codex criteria for nutrition claims.

It was considered that the proportions of foods that qualify as containing a lot or a little of each of the nutrients should be neither too small nor too large. If the criteria meant, for example, that very few foods could be categorised as having a little fat, then consumers might have difficulties in finding foods with a little fat to improve their diet. If they meant that too few foods had a lot of fat, then again consumers might have difficulties in finding foods with a lot of fat to avoid. However, on the basis that we were also advising people to cut down on fat, then it might be supposed that there should be more foods with 
a lot of fat than with a little. (Similar arguments apply to the other nutrients.) Broadly speaking, it was considered that if the cut points ensured that approximately one-third of foods had a lot of the nutrient, one-third had a little and one-third had an intermediate amount, then this would give the greatest discrimination between foods with a lot or a little or an intermediate amount.

Table 2 shows the proportions of foods in the sixth summary edition of McCance \& Widdowson's The Composition of Foods that met the Rules of Thumb criteria. It also shows the proportions adjusted for consumption (by weight) as indicated by the National Food Survey for 2000 .

Table 2 shows that, for each nutrient, different proportions of foods are categorised as meeting each of the criteria. It shows that significantly more than a third of foods - whether adjusted for consumption or not qualify for containing a little of each of the nutrients and significantly less than a third qualify for containing a lot of each of the nutrients. This seems to suggest that criteria for 'a lot' have been set too high and the criteria for 'a little' too low.

It was also considered that the criteria for the Rules of Thumb should be similar to the FAC and Codex criteria for nutrition claims. Table 3 compares the criteria. It shows that the criteria for 'a little fat', 'a little sugar' and 'a little saturates' are more stringent than the conditions for 'low fat', 'low sugar' and 'low saturates' recommended by the FAC. But the conditions for 'a lot of fibre' and 'a little sodium' are less stringent than the conditions for 'high fibre' and 'low sodium'. On balance, the Rules of Thumb are similar to the FAC conditions. Table 3 also shows that the criteria for 'a little fat', 'a little saturates' and 'a little sodium' are very close to the Codex criteria for low fat, low saturates and low sodium.

\section{A brief history of GDAs and the Rules of Thumb since the publication of Use your Label}

Since the publication of Use your Label in 1996, the GDAs for fat, saturated fat and sodium have come into common use. The GDAs published in Use your Label were not, however, called Guideline Daily Amounts but Daily Guideline Intakes (DGIs). The Daily Guideline Intakes became known as Guideline Daily Amounts because in 1998 the Institute of Grocery Distribution (IGD) published Voluntary Nutritional Labelling Guidelines to Benefit the Consumer $^{24}$, containing what they called Guideline Daily Amounts for fat and saturated fat using the values of the DGIs in Use your Label. The IGD also gave GDAs for calories using the energy base to the calculations for the DGIs in Use your Label. The IGD coined the term Guideline Daily Amounts on the basis of some qualitative research exploring consumer preferences for different terms for DGIs ${ }^{25}$.

Since 1998, GDAs for calories, fat, saturated fat and in some instances sodium and salt have been used by a number of different food manufacturers and retailers in their leaflets and on their food packets. The retailers who have used them include Waitrose ${ }^{26}, \mathrm{Asda}^{27}$, Sainsburys ${ }^{28}$, Marks and Spencer ${ }^{29}$ and the Co-op ${ }^{30}$. The manufacturers who have used them include Walkers and Heinz ${ }^{31}$. Some charities, e.g. the British Heart Foundation ${ }^{32}$, have used them in their advice about healthy eating.

The Rules of Thumb are less well-known than the GDAs. However, since 1996 they have appeared in a

Table 2 Percentages of foods in the sixth summary edition of McCance \& Widdowson's The Composition of Foods meeting the conditions for a lot and a little

\begin{tabular}{lccccc}
\hline Foods with & Total (\%) & $\begin{array}{c}\text { Weighted by } \\
\text { intake (\%) }\end{array}$ & Foods with & Total (\%) & $\begin{array}{c}\text { Weighted by } \\
\text { intake (\%) }\end{array}$ \\
\hline 'A lot of sugar' & 26 & 18 & 'A little sugar' & 41 & 34 \\
'A lot of fat' & 23 & 11 & 'A little fat' & 39 & 62 \\
'A lot of saturates' & 31 & 15 & 'A little saturates' & 43 & 58 \\
'A lot of fibre' & 15 & 9 & 'A little fibre' & 45 & 55 \\
'A lot of sodium' & 24 & 16 & 'A little sodium' & 48 & 69 \\
\hline
\end{tabular}

This table was obtained in the following way.

1. All 1235 different foods in the sixth summary edition of McCance \& Widdowson's The Composition of Foods ${ }^{18}$ were examined. Raw meat, raw pasta and human milk were removed from the list because they are either inedible or not sold by food retailers. This left 1184 different foods.

2. Foods were assigned a portion size using the Ministry of Agriculture, Fisheries and Food manual of food portion sizes $^{22}$. Where no portion size was available from this source, foods were assigned an approximate portion size using information from the Tesco, Sainsbury, Asda and Waitrose websites (nine foods).

3. Foods were classified as either whole meals and main dishes, or other foods. Foods were classified as whole meals or main dishes if the food was the main dish of a meal before additions, such as vegetables, potatoes or rice, was not eaten as a dessert or for breakfast, and had an average portion size of at least $100 \mathrm{~g}$. There were 180 whole meals and main dishes.

4. Foods were classified as having a lot or a little of each nutrient by examining nutrient levels per portion for whole meals or main dishes and per $100 \mathrm{~g}$ for all other foods. Where the categorisation of a little or a lot was unclear, either because of insufficient nutrient composition or portion size data, the food was omitted from the analysis (28 foods for the analysis of sugar levels, three for fat, 122 for saturated fat, 136 for fibre and 13 for sodium).

5 . In order to weight the foods by consumption, each food in the list was assigned to a category taken from Table B1 of the National Food Survey for $2000^{23}$. The yearly average, measured in grams per person per week, for each category was then divided equally between all the foods in the category. These values were then used as the value of each food in the analysis. 
Table 3 Comparison of the Rules of Thumb in Use your Label with Codex's and the Food Advisory Committee's (FAC) criteria for nutrition claims

\begin{tabular}{|c|c|c|c|}
\hline \multicolumn{2}{|c|}{ Use your Label } & \multirow{2}{*}{$\begin{array}{l}\text { Codex }^{10} \\
\text { No definitions }\end{array}$} & \multirow{2}{*}{$\begin{array}{c}\text { FAC }^{19} \\
\text { Low sugar }=5 \mathrm{~g} / 100 \mathrm{~g} \\
\text { and } 5 \mathrm{~g} / \text { serving }\end{array}$} \\
\hline $\begin{array}{l}\text { A lot of sugar }=10 \mathrm{~g} / 100 \mathrm{~g} \\
\text { or } 10 \mathrm{~g} / \text { serving }\end{array}$ & $\begin{array}{l}\text { A little sugar }=2 \mathrm{~g} / 100 \mathrm{~g} \\
\text { or } 2 \mathrm{~g} / \text { serving }\end{array}$ & & \\
\hline $\begin{array}{l}\text { A lot of saturates }=5 \mathrm{~g} / 100 \mathrm{~g} \\
\text { or } 5 \mathrm{~g} / \text { serving }\end{array}$ & $\begin{array}{l}\text { A little saturates }=1 \mathrm{~g} / 100 \mathrm{~g} \\
\text { or } 1 \mathrm{~g} / \text { serving }\end{array}$ & Low saturates $=1.5 \mathrm{~g} / 100 \mathrm{~g}$ & $\begin{array}{l}\text { Low saturates }=3 \mathrm{~g} / 100 \mathrm{~g} \\
\text { and } 3 \mathrm{~g} / \text { serving }\end{array}$ \\
\hline $\begin{array}{l}\text { A lot of sodium }=0.5 \mathrm{~g} / 100 \mathrm{~g} \\
\text { or } 0.5 \mathrm{~g} / \text { serving }\end{array}$ & $\begin{array}{l}\text { A little sodium }=0.1 \mathrm{~g} / 100 \mathrm{~g} \\
\quad \text { or } 0.1 \mathrm{~g} / \text { serving }\end{array}$ & Low sodium $=0.12 \mathrm{~g} / 100 \mathrm{~g}$ & $\begin{array}{l}\text { Low sodium }=0.04 \mathrm{~g} / 100 \mathrm{~g} \\
\text { and } 0.04 \mathrm{~g} / \text { serving }\end{array}$ \\
\hline
\end{tabular}

number of publications such as a British Heart Foundation leaflet ${ }^{33}$ and more recently - in a slightly modified form in some leaflets produced by the FSA ${ }^{8}$.

\section{Conclusion and recommendations}

Use your Label is now out of print but the GDAs and the Rules of Thumb that it contained are still useful to consumers. Therefore we recommend that the FSA publish a list of official GDAs for energy, fat, saturated fat, total sugar, non-milk extrinsic sugar, salt, sodium, fibre and possibly other nutrients as well, such as iron and folate.

On the grounds that the GDAs for fat, saturated fat and sodium are now widely used in food labelling and healthy eating advice, then their numerical value should not be changed. On the other hand, if the Government were to agree a new population dietary goal for fat - on the basis that fat intakes, although not yet ideal, are now close to the current goal $^{34}$ - then new GDAs for fat should be developed.

The list of official GDAs should contain GDAs for energy. We make this recommendation on pragmatic grounds. The GDAs for energy are already found on many food labels. The official list of GDAs should note the particular problems with GDAs for energy. There may be grounds for looking again at what has become commonly accepted as the GDAs for energy. Note that these were never published in Use your Label and have never been officially agreed.

Official GDAs for total sugar should ideally only be given once the Government has agreed a population dietary goal for total sugar. Official GDAs for total sugar would not be necessary if the EU nutrition labelling directive were to be revised to prescribe the labelling of non-milk extrinsic sugars rather than total sugars. Conversely, an official GDA for non-milk extrinsic sugar will be valueless until food producers provide information about the non-milk extrinsic sugar content of their foods.

Official GDAs for fibre should only be given once there is an EU-agreed definition for fibre for labelling purposes and/or all (or at least the vast majority of) food producers settle on one method for measuring fibre. If the agreed method were to be different from the Englyst or Southgate method, then the Government would need to agree a population goal for fibre as measured by that method before a GDA could be developed.

The FSA's recently published leaflets contain the Rules of Thumb in a slightly modified form ${ }^{8}$. They have only published Rules of Thumb for fat, saturated fat, sodium and sugar but not for fibre. Dropping the Rule of Thumb for fibre seems sensible given that manufacturers continue to measure fibre in a variety of ways and there is no officially agreed definition of fibre for food labelling purposes. Once there is such a definition then the FSA should publish a Rule of Thumb for fibre.

The recently re-issued leaflets containing the Rules of Thumb suggest that consumers should assess the nutrient levels of all foods, including whole meals or main dishes, on a per $100 \mathrm{~g}$ basis. This makes the new criteria for a little and a lot of fat, saturated fat, sugar and sodium less stringent than in Use your Label. For example, Tesco's cauliflower cheese claiming to be $2 \%$ fat and with $1.5 \mathrm{~g}$ fat per $100 \mathrm{~g}$ and $6.0 \mathrm{~g}$ fat per $400 \mathrm{~g}$ serving would have a little fat according to the new criteria but would not according to the criteria in Use your Label. If the FSA were to republish these leaflets they should reinstate the Rules of Thumb as originally formulated.

The Rule of Thumb for sugar in Use your Label and the recent FSA leaflets was based on a population dietary goal for non-milk extrinsic sugar. A new Rule of Thumb for sugar should be developed based on an official population dietary goal and GDAs for total sugar.

A proposed population goal and GDAs for total sugar are given in the Appendix. A proposed new Rule of Thumb for sugar would be that a lot would be about $20 \mathrm{~g}$ and a little about $4 \mathrm{~g}$.

\section{Acknowledgements}

The development of Use your Label was funded by the MAFF. M.R. and P.S. are currently supported by the British Heart Foundation. The authors would like to thank Jenny Woolfe and Ros Bratley, then at MAFF, for 
their support for the development of Use your Label. The authors are also grateful to Martin Wiseman, then of the Department of Health, for his advice on the development of GDAs and for comments on the paper. Annette Boaz and Mark Myatt were part of the original project team involved in the development of Use your Label. The views expressed in this paper are those of the authors and are not necessarily those of any government department or the FSA.

\section{References}

1 Williams C, Rayner M, Myatt M, Boaz A. Use your Label: Making Sense of Nutrition Information. Foodsense leaflet. London: Ministry of Agriculture, Fisheries and Food, 1996.

2 European Commission. Council Directive No. 90/496/EEC of 24 September 1990 on nutrition labelling for foodstuffs. Official Journal 6.10.1990; 40-4.

3 Cowburn G, Stockley L. A Systematic Review of the Research on Consumer Understanding of Nutrition Labelling. Brussels: European Heart Network, 2003.

4 Department of Health. Dietary Reference Values for Food Energy and Nutrients for the United Kingdom. Report on Health and Social Subjects No. 41. London: HMSO, 1991.

5 Bettman J R. An Information Processing Theory of Consumer Choice. Reading, MA: Addison Wesley, 1979.

6 Rayner M, Boaz A, Higginson C. Consumer use of healthrelated endorsements on food labels in the UK and Australia. Journal of Nutrition Education 2001; 33: 24-30.

7 Myatt M. MAFF food labelling project: results of the testing of the proposed Foodsense leaflet 'Use Your Label. Unpublished report, 1995.

8 Food Standards Agency (FSA). Labelling Claims. London: FSA, 2002 (and Salt, Sugar and Fat in this series).

9 European Commission. Proposal for a Regulation of the European Parliament and of the Council on Nutrition and Health Claims made on Foods. 16.7.2003 COM(2003) 424 final. Brussels: European Commission, 2003.

10 Codex Alimentarius Commission (CAC). Guidelines for Use of Nutrition Claims. CAC/GL 23-1997. Rome: CAC, 1997.

11 Department of Health (DoH). Sensible Drinking, The Report of an Inter-Departmental Working Group. London: DoH, 1995.

12 Department of Health. The Health of the Nation. A Strategy for Health in England. London: HMSO, 1992.

13 Department of Health. Nutritional Aspects of Cardiovascular Disease. Report on Health and Social Subjects No. 46. London: HMSO, 1994.

14 Department of Health. Dietary Sugars and Human Disease. Report of the Panel on Dietary Sugars. Report on Health and Social Subjects No. 37. London: HMSO, 1989.

15 Research Services Ltd. Nutrition Labelling Study Report. London: Ministry of Agriculture, Fisheries and Food, 1995.

16 Department of Health. Nutritional Aspects of the Development of Cancer. Report on Health and Social Subjects No. 48. London: HMSO, 1998.

17 Scientific Advisory Committee on Nutrition. Salt and Health. London: The Stationery Office, 2003.

18 Roe MA, Finglas PM, Church SM. McCance \& Widdowson's The Composition of Foods, sixth summary ed. London: Royal Society of Chemistry and the Food Standards Agency, 2002.

19 Ministry of Agriculture, Fisheries and Food. Food Advisory Committee Report on its Review of Food Labelling and Advertising 1990. London: HMSO, 1991.
20 Coronary Prevention Group (CPG). Nutritional Labelling of Foods: A Rational Approach to Banding. London: CPG, 1988.

21 Black A, Rayner M. Just Read the Label. London: HMSO, 1992.

22 Ministry of Agriculture, Fisheries and Food. Food Portion Sizes, 2nd ed. London: HMSO, 1988.

23 Department for Environment, Food and Rural Affairs. National Food Survey 2000. London: The Stationery Office, 2001.

24 Institute of Grocery Distribution (IGD). Voluntary Nutritional Labelling Guidelines to Benefit the Consumer. Watford, UK: IGD, 1998.

25 MMR Product and Concept Research. Additional Voluntary Nutrition Labelling Research. Final Report. Watford, UK: Institute of Grocery Distribution, 1997.

26 http://www.waitrose.com/food_drink/nutrition/ healthyeating/dailyrequirements.asp (accessed 30 May 2003).

27 http://193.201.200.191/shapeup/healthyeat.html (accessed 30 May 2003).

28 http://www.sainsburys.co.uk/labelling/ (accessed 30 May 2003).

29 http://www2.marksandspencer.com/foodmagazine/ insidestory/newyear/whatsonthelabel_.shtml (accessed 30 May 2003).

30 http://www.co-op.co.uk/ (accessed 30 May 2003).

31 http://www.heinz.co.uk/ (accessed 30 May 2003).

32 http://www.bhf.org.uk/hearthealth/index.asp?secondlevel=78\&thirdlevel=350\&artID=407 (accessed 30 May 2003).

33 British Heart Foundation (BHF). Guide to Food Labelling. London: BHF: undated.

34 Henderson L, Gregory J, Irving K, Swan G. The National Diet and Nutrition Survey: Adults aged 19 to 64 years. Vol. 2. London: HMSO, 2003.

\section{Appendix - A method of calculating a population dietary goal, new GDAs and a new Rule of Thumb for total sugar}

The first step in calculating a GDA for total sugar would be to develop a population dietary goal. There are various ways by which this could be done. The method described here was the method used to derive a population goal for total sugar for the purposes of developing the Coronary Prevention Group's banding scheme ${ }^{21}$.

First we need to make estimates for the total sugar, nonmilk extrinsic, non-milk intrinsic and milk sugar intakes in the UK. From the recently published report of the National Diet and Nutrition Survey (NDNS) we can estimate that these are about 20\%,13\%, 5\% and $2 \%$ as percentages of food energy, respectively ${ }^{34}$.

COMA 1991 indicates that non-milk extrinsic sugar intake should be about 11\% of food energy. COMA 1991 makes no recommendation for milk sugar - neither an increase nor a reduction; we therefore suggest that it should remain at its current level of about $2 \%$. The NDNS indicates that fruit contributes about $42 \%$ of intrinsic sugar intake; vegetables including potatoes contribute about $15 \%$ and bread contributes about 11\%. COMA 1994 recommends that 'consumption of vegetables, fruit, potatoes and bread is increased by at least $50 \%, 11$. 
We therefore suggest that intrinsic sugar intake should rise from $5 \%$ to $7 \%$ on the basis of the following calculation: $\{0.5 \times[(42+15+11) / 100] \times 5\}+5$.

Therefore we recommend that the population average intake for total sugar, by addition, should be $21 \%$ of food energy intake: i.e. $11 \%+7 \%+2 \%$ (with rounding). This converts to $19 \%$ of total energy intake on the basis that the
NDNS suggests that food energy should account for $93 \%$ of total energy intake.

Given this population dietary goal for total sugar, we then calculate that the GDAs for total sugar should be $130 \mathrm{~g}$ for men and $100 \mathrm{~g}$ for women. A Rule of Thumb for sugar would then be that a lot would be about $20 \mathrm{~g}$ and a little about $4 \mathrm{~g}$. 